\title{
CONSTITUIÇÃO E EXTINÇÃO DE MICROEMPRESAS EM JUAZEIRO DO NORTE-CE
}

\author{
CONSTITUTION AND EXTINCTION OF MICRO-ENTERPRISES \\ IN JUAZEIRO DO NORTE-CE
}

\author{
CONSTITUCIÓN Y EXTINCIÓN DE MICROEMPRESAS \\ EN JUAZEIRO DO NORTE-CE
}

Maria Jeanne Gonzaga de Paiva Ronichélida Xavier Ramalho

\begin{abstract}
Resumo: As microempresas-ME's, do ponto de vista do desenvolvimento social e econômico, atuam como suporte para a geração de emprego e renda, reduzindo as desigualdades entre indivíduos e regiões, contribuindo com o fortalecimento da economia. Uma de suas características é a de apresentar altas taxas de constituição e natalidade. Apesar da causa da extinção das ME's estar associada à falta de planejamento ou de compromisso com a organização, estes não constituem fatores exclusivos, visto que a ausência de políticas de apoio ou uma conjuntura econômica desfavorável também podem contribuir com a mortalidade. Nesse contexto, tem-se como objetivo conhecer a dinâmica de constituição e extinção das ME's dos setores de comércio, indústria e serviços em Juazeiro do Norte - CE no período de 1997 a 2007. Para isso, foram utilizadas pesquisas bibliográfica e descritiva com dados de natureza secundária obtidos na JUCEC, em Fortaleza, calculando-se os índices de constituição e extinção das referidas empresas no período considerado, constatando-se no setor de serviços os maiores índices de constituição, assim como de extinção. De forma geral, pôde-se verificar também que, conforme ocorrido no país, as ME's em Juazeiro do Norte obtiveram melhores taxas de sobrevivência, apesar de, em certos anos, os índices de extinção terem-se mantido elevados.
\end{abstract}

Palavras-chave: Microempresas. Constituição. Extinção. Juazeiro do Norte.

\begin{abstract}
From the point of view of social and financial development, micro-companies act as income and employment generation agents, thus reducing inequalities among individuals and regions and contributing to strengthen the economy. One of their main characteristics is their high birth and bankruptcy rates. Although the reason for micro-companies closing down is usually associated to lack of adequate planning or organizational responsibility, these are not exclusive factors, as the absence of support policies or unfavorable economic conditions can also contribute to corporate bankruptcy. In this context, our goal is to learn about birth and mortality dynamics for micro-companies of the trades, industrial and services sector in Juazeiro do Norte -CE, for the 1997-2007 period. For this matter, bibliographic and descriptive research was used together with additional data obtained at the Board of Trade of Ceará State in Fortaleza to calculate birth and bankruptcy rates for the referred companies in the aforementioned period. The highest rates for both starting and ceasing business were observed in the services sector. Generally speaking, we can also verify that as it has happened all over the country, during this period, micro-companies of Juazeiro do Norte obtained better survival rates, although in some years bankruptcy rates have been considerably high.
\end{abstract} Keywords: Micro-companies. Birth. Bankruptcy. Juazeiro do Norte.

Resumen: Desde el punto de vista del desarrollo social y económico, las microempresas (ME's) actúan como soporte para la generación de empleo e ingresos, reduciendo las desigualdades entre individuos y regiones y contribuyendo al fortalecimiento de la economía. Una de sus características es la de presentar altas tasas de natalidad y mortalidad. A pesar de que la causa da extinción de las ME's está asociada a la falta de planificación o de compromiso con la organización, estos no son factores exclusivos, ya que la ausencia de políticas de apoyo o una coyuntura económica desfavorable también pueden contribuir con la mortalidad de empresas. En este contexto, el objetivo es conocer la dinámica de constitución y extinción de las ME's de los sectores de comercio, industria y servicios en Juazeiro do Norte - CE entre 1997 y 2007. Para ello fueron utilizadas investigaciones bibliográficas y descriptivas con datos de naturaleza secundaria obtenidos en la JUCEC de Fortaleza, calculando los niveles de constitución y extinción de las referidas empresas durante el período considerado. El sector de servicios presentó las tasas más altas, tanto de constitución como de extinción. En términos generales, se puede verificar también que al igual que en el resto del país, las ME's de Juazeiro do Norte obtuvieron buenas tasas de supervivencia, a pesar de que en algunos años las tasas de extinción se mantuvieron elevadas.

Palabras clave: Microempresas. Constitución. Extinción. Juazeiro do Norte

\footnotetext{
*Artigo recebido em agosto de 2013
}

Aprovado em outubro de 2013 


\section{INTRODUÇÃO}

No Brasil, as micro e pequenas empresas (MPEs) existem em maior escala em todas as regiões, exercendo papel fundamental no seu processo de desenvolvimento socioeconômico. Para Souza (1997), o crescimento econômico é uma variação quantitativa do produto, já o desenvolvimento envolve mudanças qualitativas no modo de vida das pessoas, das instituições e das estruturas produtivas. Dessa forma, as microempresas (MEs) contribuem com o crescimento e desenvolvimento do país, tendo em vista que contribuem com a formação do Produto Interno Bruto (PIB) e agem promovendo o bem-estar social.

Apesar da relevância das MEs, a maioria fracassa por falta de preparo e apoio adequado, devido às exigências burocráticas ou devido à carência de crédito e de uma política de apoio e incentivo. É neste segmento que se encontram as maiores taxas de natalidade, como também as empresas que mais encerram suas atividades. São várias as causas desses encerramentos, não existindo um fator exclusivo que ocasiona a mortalidade, mas sim um conjunto de fatores contribuintes.

Nesse contexto, esta pesquisa envolve a necessidade de conhecer melhor a dinâmica de constituição e extinção das microempresas por setor (comércio, indústria e serviços) em Juazeiro do Norte - CE, no período de 1997 a 2007. Esse recorte de tempo teve como objetivo perceber melhor esse movimento interno responsável por abertura de novos negócios, assim como pelo seu encerramento, utilizando-se de pesquisas bibliográficas e descritivas com dados de natureza secundária, obtidos junto à Junta Comercial em Fortaleza - CE.

A qualificação do porte das empresas foi definida pelo critério de faturamento da Junta Comercial que define a ME como a pessoa jurídica e a firma mercantil individual que tiver receita bruta anual igual ou inferior a $R$ \$ 244.000,00. (JUNTA COMERCIAL DO ESTADO DO CEARÁ, 2005).

Os índices de constituição (1) e extinção (2) das microempresas foram calculados em forma percentual, através das seguintes fórmulas:

$$
\begin{aligned}
& \text { IC }=\text { ECA/ETAnt } * 100 \text { e, } \\
& \text { IE }=\text { EFA/ETAnt*100. }
\end{aligned}
$$

Onde: IC = Índice de constituição; IE = Índice de extinção: $E C A=n^{\circ}$. de estabelecimentos constituídos em um ano; EFA $=n^{\circ}$. de estabelecimentos extintos no ano; ETAnt $=$ total de estabelecimentos existentes no ano anterior.

O estudo foi realizado no município de Juazeiro do Norte - $\mathrm{CE}$, localizado no extremo sul do estado do Ceará, distante cerca de 560 $\mathrm{km}$ de Fortaleza pela BR 116, com uma área de $249 \mathrm{~km} 2$. Com população estimada em 242.139 habitantes, um Produto Interno Bruto
(PIB) de R\$ 1.098 .232 e PIB per capita de R\$ 4.564, conforme o Instituto Brasileiro de Geografia e Estatística (2007). Juazeiro do norte é o terceiro município mais populoso do Ceará e a quinta maior economia do estado

A estrutura do artigo ficou estabelecida da seguinte forma: na primeira seção, serão feitas algumas considerações sobre a importância das MEs para o desenvolvimento social e econômico, assim como a discussão sobre alguns aspectos da mortalidade das MEs e, por fim, um estudo sobre a constituição e extinção das MEs juazeirenses.

\section{AS MICROEMPRESAS COMO PROPULSORAS DO DESENVOLVIMENTO SOCIOECONÔMICO}

As MPEs brasileiras correspondem a $98 \%$ do total de estabelecimentos do setor produtivo, sendo que cerca de $56 \%$ encontram-se no setor de comércio, $30 \%$ no setor de serviços e $14 \%$ no setor industrial (BEDÊ, 2006). Elas são fundamentais para o desenvolvimento do país, por serem grandes contribuintes na geração de emprego e na melhoria da distribuição de renda, contribuindo ainda para o processo de inclusão social, com a redução das desigualdades sociais. Visam atender, sobretudo, as necessidades básicas, atuando também no fortalecimento da classe média e na redução das desigualdades regionais.

A importância das MPEs no Brasil é notável, mas, para que elas possam de fato contribuir com o desenvolvimento do país, é necessário que haja o suporte de empreendedores inovadores: a sua existência e de novas combinações produtivas é, segundo Schumpeter (1997), condição necessária para o processo de desenvolvimento econômico.

As MPEs contribuem com cerca de $20 \%$ do PIB. (SEBRAE, 2006). Possuem relevância social, pois geram boa parte dos empregos estabelecidos no país, além de importância política, na medida em que atomiza a massa trabalhadora assalariada.

A contribuição das MPEs para a redução das desigualdades regionais, deve-se em parte, a sua descentralização nos últimos anos. De acordo com Bedê (2006), entre 2000 e 2004, o número total de MPEs cresceu $22 \%$. As regiões que apresentaram as maiores taxas de expansão no número de MPEs, neste período, foram as regiões Norte (expansão de $29,1 \%$ ), Centro-Oeste $(27,2 \%)$, e Nordeste $(24,9 \%)$, em parte, estas maiores taxas devem-se a tendência à desconcentração regional das atividades produtivas. Entretanto, apesar dessa tendência e do aumento das taxas de expansão nas regiões Norte, Centro-Oeste e Nordeste, verifica-se ainda uma grande concentração em alguns estados, onde cerca de $85 \%$ delas encontravam-se nos dez maiores estados brasileiros: São Paulo $(30,7 \%)$, Minas 
Gerais $(11,6 \%)$, Rio Grande do Sul $(10,7 \%)$ Paraná(79,7\%)., Rio de Janeiro $(610,7 \%)$, Santa Catarina $(5,3 \%)$, Bahia $(4,5 \%)$, Goiás (3\%), Ceará $(2,9 \%)$ e Pernambuco $(2,4 \%)$.

As MPEs possuem grande mobilidade no mercado, ou seja, todos os anos é registrado um número expressivo de aberturas de empresas e também um número elevado de fechamentos. (SEBRAE, 2005). Do ponto de vista da avaliação macroeconômica que se fazia das MPEs, elas passariam por renovações naturais, o que levaria a crer que os postos de trabalho gerados seriam compensados com o fechamento de outros tantos postos, tornando constante o tamanho da fatia do emprego nas MPEs. O que se observa é que elas são responsáveis por $67 \%$ dos empregos estabelecidos no país, conforme o Sebrae (2006), e com o problema do desemprego, a criação de postos de trabalho por meio destes empreendimentos torna-se essencial para o desenvolvimento.

Cada vez mais as MEs estão participando da dinâmica de geração tecnológica, devido à revolução da informática e ao crescimento da competição global, onde a renovação dos produtos e serviços prestados é essencial para a sua permanência no mercado. Para realizar sua função e impulsionar o desenvolvimento, o empresário necessita de duas coisas: "de um pacote de inovações tecnológicas ainda não utilizadas e aptas a serem postas em prática; e, de linhas de crédito de curto e longo prazo, para que possa transformar capital em meios de produção, adotar novos métodos e gerar novos produtos" (SOUZA, 1999, p. 179). A geração de tecnologia é o alicerce para o desenvolvimento das empresas que buscam a competitividade.

Apesar da expansão das atividades que vêm atender novas demandas, devido à modernização da sociedade, exigência e satisfação do consumidor (como livrarias, serviços de informática, transporte, entre outros), o que se observa é uma forte presença de MPEs em atividades voltadas ao atendimento das necessidades básicas da população, como alimentação, vestuário e habitação. Conforme o Sebrae (2005), no setor de comércio, em 2004, sobressairam-se o comércio de alimentos $(11 \%)$, vestuário $(11 \%)$ e de material de construção (7\%). No setor de serviços, a maior incidência foi nos serviços prestados às empresas $(33 \%)$, serviços de alojamento e alimentação (24\%), e serviços de transportes terrestres (11\%). Já no setor industrial, a maior proporção foram nas indústrias de construção civil $(25 \%)$, confecções $(12 \%)$, alimentos e bebidas (12\%).

Assim, nas MPEs do comércio, em geral, há forte presença de estabelecimentos que oferecem produtos de baixo valor unitário, vendidos no varejo e associados ao atendimento das necessidades básicas da população. Nas MPEs do setor de serviços, há forte presença de empreendimentos formados por profissionais liberais (advogados, contadores, engenheiros). parte de suas atividades atende a necessidades não ligadas à subsistência das pessoas, consideradas atividades menos essenciais, como atividades recreativas e de entretenimento e manutenção físico-corporal. Nas MPEs da indústria, a maioria dos empreendimentos tem baixo volume de capital, a tecnologia é de domínio público e os produtos são voltados ao atendimento das necessidades básicas da população.

Quando as MPEs se unem e passam a praticar simultaneamente atos de competição e cooperação, passam a atuar na forma de cluster - conjunto numeroso de empresas, geralmente pequenas, em que cada uma executa estágios do processo de produção, participando do mesmo negócio, embora cada uma seja uma entidade autônoma. Na ideia marshalliana (MARSHALL, 1982), são os chamados "distritos industriais". A definição de Marshall leva a crer que, quando as MPEs se unem, conseguem não só se inserir num ambiente favorável à industrialização, como também propiciar uma aceleração do processo de desenvolvimento industrial, já que geram dinamismo econômico nas áreas onde se instalam, promovendo mudança do perfil econômico de regiões antes deprimidas.

As MPEs industriais do Brasil são as que mais exportam, porém apresentam no volume total de exportações uma participação reduzida. Muñoz (1986 apud Souza, 1999) mostrou que a abertura da economia ao mercado externo proporciona um maior desenvolvimento da classe empresarial. Assim, apesar de as exportações realizadas pelas MEs ainda apresentarem pouca expressividade, torna- se necessária a adoção de políticas de apoio às vendas externas, visando à ampliação das opções de mercados e ao desenvolvimento empresarial.

Conforme a Fundação Centro de Estudos do Comércio Exterior (2005), no período de 1998 a 2003, houve aumento no número de MEs industriais exportadoras no país. Tendo sido definida como ME exportadora a empresa industrial com até 19 pessoas ocupadas e exportações anuais de até US\$300 mil. Os principais resultados obtidos foram: o número de microempresas industriais exportadoras num total de 2.627 no ano de 2003, com valor exportado de US\$132,4 milhões, e participação de $0,2 \%$ nas exportações totais das empresas industriais. O valor médio exportado pelas firmas desse porte alcançou US\$ 50,4 mil. Apesar de pequeno o crescimento das exportações das MEs, elas têm exportado mais do que antes, uma das causas é a formação de associações de exportadores, onde juntos, conseguem reduzir custos.

\subsection{Microempresas: aspectos sobre a mortalidade dos negócios}

Diante da importância das MEs como propulsoras do desenvolvimento socioeconômico do país, verifica-se que o potencial total destas 
não é adequadamente aproveitado, visto que, são elevadas as suas taxas de extinção, apesar de ser também neste segmento que se encontram as maiores taxas de constituição. Na Bahia, entre 1997 e 2000, 45,5\% das MEs fecharam suas portas antes de quatro anos de atividades. (SILVA, 2004). Em São Paulo mais da metade não conseguem sobreviver ao quarto ou quinto ano de vida: (BEDÊ, 2005).

Existem vários fatores que contribuem para a falência, assim, analisaremos as principais causas da mortalidade que, conforme o Sebrae (2005), são: ausência do comportamento empreendedor; falta de planejamento; má gestão empresarial; insuficiência de políticas de apoio; conjuntura econômica desfavorável; e problemas pessoais dos empresários.

Schumpeter (1997) associou o empreendedor ao conceito de inovação, necessário ao processo de desenvolvimento. O empresário com espírito empreendedor desenvolvido tem mais chances de ser bem sucedido. A atitude empreendedora deve ser desenvolvida no indivíduo antes da abertura do negócio, pois a ausência do empreendedorismo após a abertura comprometerá o funcionamento da empresa que poderá ir à falência.

Na concepção de Adizes (1998), a perda da capacidade empreendedora é um motivo de envelhecimento, que pode resultar na morte. Assim, é o espírito empreendedor que dá vida à organização, o seu desaparecimento constitui a própria morte organizacional.

A ausência do planejamento do negócio antes da abertura é um fator de mortalidade, pois envolve importantes informações sobre consumidor, fornecedor e concorrente. "Infelizmente, a maioria dos pequenos empresários não tem condições ou não sabe ao certo planejar metas para sua empresa" (AMORIM, 2000, p.112). A questão do planejamento também envolve a melhor localização do ponto de distribuição, um quadro de bons funcionários e definição de metas.

Segundo Schumpeter (1997), a função empresarial aparece misturada com outros tipos de atividade, o que envolve o fenômeno da liderança, característica fundamental ao bom gestor de empresas que deve sempre comprometer-se com a produção e a entrega, buscar inovações, monitorar o fluxo de receitas e despesas, buscar apoio profissional se necessário, realizar controle de custos, etc.

A falta também de políticas que visem desburocratizar e reduzir custos de abertura, diminuir encargos e impostos, facilitar o acesso ao crédito e financiamentos com linhas específicas para as MEs e facilitar o acesso às compras governamentais mostram-se, em muitos casos, como um condicionante da mortalidade.

Conforme Bedê (2005), das empresas encerradas entre 1999 e 2003, foi menor o acesso às políticas de apoio do que as que sobreviveram, ou seja, a carência de ações pode contribuir para a expansão da mortalidade. Assim, o papel do governo, ao tentar discipli- nar as ações das empresas, através de suas políticas de apoio e incentivom, é importante para a sua sustentação.

\section{MICROEMPRESAS JUAZEIRENSES: constituição e extinção de 1997 a 2007}

As MEs dependem de políticas que visem ao seu fortalecimento, incluindo a menor burocracia possível, baixos encargos e impostos, acesso ao crédito, a financiamentos e às compras governamentais. No entanto, o que se percebe é que a insuficiência das políticas de apoio é tida como uma das principais causas da mortalidade.

Em 1996, foi implantado o Simples Federal que correspondia a um regime de recolhimento de impostos, simplificado e com alíquotas menores para MPEs, sendo os seus efeitos dispersos em um espaço de até dois ou três anos após a sua criação. (BEDÊ, 2005).

Foi visando assegurar um tratamento jurídico diferenciado e simplificado, e facilitar a constituição e o funcionamento da MPE, que foi criado o Estatuto da Microempresa e da Empresa de Pequeno Porte em 1999 (BRASIL, 1999), no qual o poder executivo estabeleceu mecanismos fiscais e financeiros de estímulo às instituições financeiras privadas, no sentido de que se mantivessem linhas de crédito específicas para as MPEs.

Nesse contexto surgiu o microcrédito e o interesse de instituições como o Banco Nacional de Desenvolvimento Econômico e Social (BNDES) e o Banco do Nordeste do Brasil (BNB) em atuar nesse segmento. Conforme o Banco Nacional de Desenvolvimento Econômico e Social (2004), de 1996 a 2000, foi maior o número de empresas que conseguiram continuar ativas no país, contribuindo com a redução da mortalidade e geração de empregos.

Em Juazeiro do Norte, comparando os anos de 1997 e 2000, verificou-se também uma redução nos índices de extinção de 0,87\% para $0,31 \%$ (na indústria), 0,83\% para $0,79 \%$ (no comércio) e $2,25 \%$ para $1,22 \%$ (nos serviços). No período de 1997 a 2000, as MEs do município com atividades industriais e comerciais obtiveram suas menores taxas de extinção, ocorridas no ano de 1999 (0,25\% e 0,46\% respectivamente para indústria e comércio). Isto ocorreu em parte devido às medidas adotadas na segunda metade dos anos 1990 (Tabela 1).

No período de 1998 a 2001, as MPEs do país tiveram um crescimento médio de 2,9\% ao ano em termos reais, acompanhando o crescimento das médias e grandes, que foi de 3,0\%. (INSTITUTO BRASILEIRO DE GEOGRAFIA E ESTATÍSTICA, 2001). As taxas de constituição das MEs juazeirenses mantiveram-se elevadas: $7,48 \%, 7,45 \%$ e $11,48 \%$ em 1999 , para os setores de indústria, comércio e serviços, associada a uma redução na extinção: indústria $(0,25 \%)$, comércio $(0,46 \%)$, e serviços 
$(0,84 \%)$, em relação às taxas do ano de 1997 (Tabela 1).

De 2000 a 2001, houve crescimento do número de empresas cadastradas no país na ordem de $11,4 \%$, devido ao aumento da natalidade de $18,7 \%$ para $21,8 \%$ e à redução da mortalidade de $12,4 \%$ para $9 \%$, conforme Instituto Brasileiro de Geografia e Estatística (2001). Este fato foi evidenciado no setor de serviços de Juazeiro do Norte, onde a taxa de natalidade saltou de $9,62 \%$ para $14,93 \%$ e, ao mesmo tempo, houve uma redução da taxa de mortalidade de $1,22 \%$ para $0,85 \%$, de 2000 a 2001 (Tabela 1).

O Banco Nacional de Desenvolvimento Econômico e Social (2004) acredita que a ampliação da oferta de crédito e medidas para reduzir os riscos inerentes ao seu financiamento podem ter contribuído com as taxas de sobrevivência e com o aumento da produção e do emprego nos últimos anos. Apesar da disponibilidade de crédito melhorar as condições de operação das empresas, ela não garante a sobrevivência.

No que diz respeito a crédito, existe o Crediamigo do BNB que tem como principal público microempresários com necessidades de ampliação de capital de giro e de trabalho. Dos estados de atuação do BNB, o Ceará lidera o número de empréstimos, atendidos $81 \%$ dos municípios; em 2002, os recursos para microempresários cearenses somaram $\mathrm{R} \$ 44$ milhões, conforme o Banco do Nordeste do Brasil (2003).

O programa já beneficiou milhares de empresários por meio da oferta de crédito, contribuindo para a permanência das MEs no setor e com a redução das taxas de extinção.

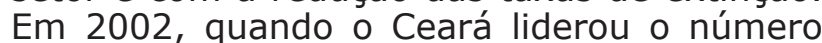
de financiamentos, os índices de extinção em Juazeiro atingiram 0,81\% (setor industrial), $1,05 \%$ (setor comercial) e 1,11\% (setor de serviços). Estes índices não foram reduzidos quando comparados há anos posteriores, isto não significa que a maior oferta de crédito no ano de 2002 tenha sido insuficiente na redução da mortalidade, mas pode indicar que a disponibilidade de crédito não garante a sobrevivência ou indica a necessidade de um espaço de tempo para que os resultados da oferta de crédito possam ser vistos. É o que ocorreu nos anos de 2003, 2004 e 2005, onde houve redução gradativa no número de empresas encerradas, atingindo taxas de 0,54\%,0,96\%, e $0,77 \%$, respectivamente. para os setores de indústria, comércio e de serviços em 2005, em Juazeiro do Norte (Tabela 1).

O número de MPEs que está conseguindo sobreviver no mercado aumentou para $78 \%$ entre 2003 e 2005, no país. Em relação ao índice de sobrevivência das empresas do Ceará, verificou-se que o estado se manteve na média nacional, com taxa de $78 \%$. (SEBRAE, 2006). De acordo com os dados da Secretaria da Fazenda, para as MEs cearenses no período de 1999 a 2005, verificou-se também um aumento na sobrevivência entre os anos de 2003 e 2005, com uma redução da mortalidade já a partir do ano de 2000.

Verificou-se também um aumento nas taxas de sobrevivência das MEs juazeirenses (o que pode ser comprovado pela redução dos índices de extinção), principalmente nos setores de indústria e de comércio, que apresentaram a seguinte evolução: $0,71 \%$ para o ano de 2003; 0,55\% em 2004 e 0,54\% em 2005 para as MEs industriais. 1,26\% para o ano de 2003; 0,97\% em 2004 e 0,96\% em 2005 (Tabela 1).

De acordo com o Instituto Brasileiro de Geografia e Estatística (2006), mais de 90\% das empresas criadas no país, entre 2000 e 2006, foram MEs. Entretanto, em 2006, sua participação recuou em relação à observada em 2005. O Instituto Brasileiro de Geografia e Estatística (2006) revelou ainda que, entre os anos de 2000 a 2006, a taxa média de entrada das unidades locais no mercado (Rio de Janeiro, São Paulo, Rio Grande do Sul e Alagoas) foi de $20,3 \%$, enquanto a taxa média de saída foi de $15,1 \%$. As maiores taxas médias de entrada e de saída das unidades locais e do pessoal assalariado no país, entre 2000 e 2006, foram em estados da região Norte, como Amapá, Roraima, Acre e Tocantins. Já as menores taxas de entrada foram em Minas Gerais, Espírito Santo, São Paulo e Rio de Janeiro.

Em 2006, o Amapá obteve taxa de constituição de $19,9 \%$, superior a de estados como São Paulo que obteve taxa de 15,8\%, (INSTITUTO BRASILEIRO DE GEOGRAFIA E ESTATÍSTICA, 2007). Com o aumento das taxas de constituição no país, pode ocorrer uma descentralização de empresas para as demais regiões brasileiras.

Bedê (2006) acredita que a melhora do perfil empreendedor, combinado a fatores macroeconômicos como o crescimento da economia, a estabilidade de preços e a recuperação da renda do trabalhador, favoreceram a queda da mortalidade entre as empresas com até quatro anos de atividades.

Em 2006, o Simples Federal foi substituído pelo Simples Nacional. Entre julho de 2007 e julho de 2008, 500 mil novas empresas do setor se formalizaram no país, juntando-se às mais de 1,5 milhão que aderiram ao Simples com a criação do regime, incluindo aquelas que já eram optantes do Simples quando o regime entrou em vigor (SEBRAE, 2008a).

Assim, o aumento do número de empresas formalizadas contribui para a expansão das taxas de constituição no país. Em Juazeiro do Norte, os índices de constituição se mantiveram elevados: 5,11\% para empresas com atividades industriais, $4,44 \%$ e $10,17 \%$ para empresas com atividades comerciais e de serviços, respectivamente, em 2007 (Tabela 1).

O Sebrae (2008) ainda ressalta que, entre os benefícios concedidos pelo Simples Nacional, houve efetiva redução dos tributos para as MPEs, a consolidação de incentivos e be- 
Tabela 1 - Índices de constituição e extinção das microempresas juazeirenses nos setores de comércio, indústria e serviços no período de 1997 a 2007.

\begin{tabular}{ccccccc}
\hline \multirow{2}{*}{ Anos } & \multicolumn{2}{c}{ Índices de constituição (\%) } & \multicolumn{3}{c}{ Índices de extinção (\%) } \\
\cline { 2 - 7 } & comércio & indústria & serviços & comércio & indústria & serviços \\
\hline 1997 & 9,18 & 8,41 & 12,91 & 0,83 & 0,87 & 2,25 \\
1998 & 7,02 & 8,63 & 10,18 & 0,87 & 0,54 & 0,55 \\
1999 & 7,45 & 7,48 & 11,48 & 0,46 & 0,25 & 0,84 \\
2000 & 6,69 & 6,67 & 9,62 & 0,79 & 0,31 & 1,22 \\
2001 & 6,46 & 7,80 & 14,93 & 0,75 & 0,36 & 0,85 \\
2002 & 5,92 & 6,38 & 11,11 & 1,05 & 0,81 & 1,11 \\
2003 & 4,57 & 4,82 & 7,41 & 1,26 & 0,71 & 0,67 \\
2004 & 4,23 & 3,89 & 9,57 & 0,97 & 0,55 & 0,95 \\
2005 & 4,38 & 5,74 & 8,91 & 0,96 & 0,54 & 0,77 \\
2006 & 4,06 & 5,34 & 9,49 & 1,17 & 0,74 & 2,15 \\
2007 & 4,44 & 5,11 & 10,17 & 1,91 & 1,41 & 2,33 \\
\hline
\end{tabular}

Fonte: Elaborado pela autora a partir dos dados da JUNCEC em Fortaleza-CE

nefícios fiscais, ocorrendo um crescimento de $5,85 \%$ no número de empregados formais no setor e de $13,82 \%$ na abertura de empresas, e o aumento da arrecadação de certos impostos como o Imposto Sobre Serviços (ISS), no país.

Para as empresas paulistas o índice de mortalidade empresarial caiu nos últimos dez anos, isto significa que estão sobrevivendo mais e de forma mais competitiva. A redução significa que, enquanto em 1998 cerca de 100 mil empresas fechavam as portas, em 2007, esse número caiu para cerca de 80 mil empresas (SEBRAE, 2008b).

Ao caracterizar as empresas ativas no município de Passo Fundo - RS, em 1997, entre as extintas, os percentuais foram de $24 \%$ no setor de comércio, $28 \%$ no setor industrial e $48 \%$ no setor de serviços, o que demonstrou também maior vulnerabilidade no setor de serviços, fato que possivelmente decorreu do reduzido volume de capital necessário à atividade, o que facilitou a saída de empresas do mercado (PANDOLFO; VELOSO, 2000).

No período de 1995 a 2000, em Londrina, no Paraná, das 119 empresas do setor de serviços, $85,71 \%$ não sobreviveram aos dois primeiros anos; das 134 empresas do comércio, $72,73 \%$ tiveram seu encerramento no mesmo período; e na indústria, quase $56 \%$ das empresas foram extintas até o segundo ano de atividade, o que demonstra que a mortalidade ocorreu mais cedo nas empresas de serviços (DUTRA, 2002).

De acordo com Dutra e Previdelli (2005), as empresas de serviços são fáceis de ser criadas e fechadas, por não precisarem de alto volume em capital inicial. Este fato é comprovado pela análise dos índices de constituição e extinção das MEs de Juazeiro do Norte, onde as empresas de serviços apresentaram maior vulnerabilidade, traduzindo-se em maiores facilidades de saída do setor na década em questão, estas também apresentaram as maiores taxas de constituição em todos os anos analisados. Esta característica das MEs de serviços (com maiores chances de entrar e sair do setor) pode indicar a necessidade de desenvolver políticas específicas visando assegurar sua sobrevivência.

Este fato foi observado em Juazeiro do Norte no ano de 1997, onde o setor de serviços também apresentou maior vulnerabilidade, com taxa de extinção de 2,25\%, superior às taxas dos setores de comércio e indústria no mesmo ano, quando obtiveram, respectivamente, taxas de $0,83 \%$ e $0,87 \%$, ou seja, as MEs de serviços foram as que mais fecharam as portas no ano de 1997 . O setor de serviços apresentou as maiores taxas de extinção em quase toda a década analisada, com exceção dos anos de 1998, 2003, 2004 e 2005, quando as maiores taxas foram no setor de comércio.

\section{CONSIDERAÇÕES FINAIS}

As MPEs têm um importante papel na economia brasileira. Ainda que de forma insuficiente, este segmento tem começado a receber a atenção das instituições e do Governo. O Sebrae conclui que as empresas abertas que estão conseguindo se manter no mercado têm aumentado na última década. O país passou por mudanças que proporcionaram um ambiente mais favorável às empresas, sobretudo devido aos mecanismos de apoio instituídos e que podem ter contribuído para a redução das taxas de mortalidade, como: o Simples Federal que contribuiu com as taxas de sobrevivência; o aumento dos programas de crédito, com linhas específicas para as MEs; o Simples $\mathrm{Na}$ cional que incentivou a formalização de empresas, contribuindo com o aumento das taxas de constituição no país e ações do Sebrae no 
intuito de promover o aprimoramento do espírito empreendedor.

De modo geral, observou-se, com a análise dos índices das MEs juazeirenses, que houve melhoria nas taxas de sobrevivência apesar de, em certos anos, terem ocorrido elevação da mortalidade. A melhora nos números das empresas que se mantiveram ativas parece indicar que as políticas desenvolvidas para este segmento estão gerando benefícios, mas ainda não suficientes, para seu desenvolvimento sustentado.

Pelos índices de extinção das MEs do município, observou-se que, entre os três setores, o de serviços foi o mais afetado, apresentando as maiores taxas de extinção em quase todos os anos e também as maiores taxas de constituição em toda a década. Aparentemente, a ampliação das medidas de apoio tem contribuído para a redução da mortalidade, mas ainda é necessário incrementar os incentivos, com a redução dos impostos, da burocracia, ampliação do crédito e acesso à tecnologia, sobretudo no setor de serviços que apresenta maior vulnerabilidade no mercado.

\section{REFERÊNCIAS}

ADIZES, I. Os ciclos de vida das organizações: como e por que as empresas crescem e morrem e o que fazer a respeito. 4 ed. São Paulo: Pioneira, 1998.

AMORIM, L. Porque as empresas quebram. Salvador: Casa da Qualidade, 2000.

BEDÊ, M.A. (Coor.). Onde estão as micro e pequenas empresas no Brasil. São Paulo: SEBRAE, 2006.

Sobrevivência e mortalidade das empresas paulistas de 1 a 5 anos. São Paulo: SEBRAE, 2005.

BANCO DO NORDESTE DO BRASIL. 2003. Disponível em: <www.bnb.gov.br>. Acesso em: 10 dez. 2008.

\section{BANCO NACIONAL DE DESENVOLVIMENTO} ECONÔMICO E SOCIAL. 2004. Disponível em: <www.bndes.gov.br>. Acesso em: 12 jan. 2009.

DUTRA, I. de S. O perfil do empreendedor e a mortalidade de micro e pequenas empresas Londrinenses. Paraná: Londrina, 2002.
DUTRA, I. de S.; PREVIDELLI, J. J. Fatores condicionantes da mortalidade de empresas: estudo dos empreendedores de micro e pequenas empresas paranaenses. Revista Capital Científico, v. 3, n. 1, jan./dez. 2005.

BRASIL. Lei $n^{\circ}$ 9.841. Institui o Estatuto da Microempresa e da Empresa de Pequeno Porte, dispondo sobre o tratamento jurídico diferenciado, simplificado e favorecido previsto nos arts. 170 e 179 da Constituição Federal. Brasília, DF, 05 out. 1999.

\section{FUNDAÇÃO CENTRO DE ESTUDOS DO} COMÉRCIO EXTERIOR. 2005. Disponível em: <www.funcex.com.br>. Acesso em: 10 mar. 2008.

\section{INSTITUTO BRASILEIRO DE GEOGRAFIA E} ESTATÍSTICA. 2001. Disponível em: <www. ibge.gov.br>. Acesso em: 23 mar. 2007.

2006. Disponível em: <www.ibge. gov.br>. Acesso em: 15 jan. 2009. 2007. Disponível em: < www.ibge. gov.br>. Acesso em: 15 jan. 2009.

JUNTA COMERCIAL DO ESTADO DO CEARÁ. Empresas contam com Central Fácil como aliado empresarial. JUCEC em notícias, Ceará, maio/ago. 2005.

MARSHALL, A. Princípios de economia tratado introdutório. São Paulo: Abril Cultural, 1982. v. I.

PANDOLFO, M. S. de M.; VELOSO, P. R. Análise da mortalidade das micro e pequenas empresas e evidências para o município de Passo Fundo - RS. Teoria e Evidência Econômica, Passo Fundo, v. 8, n. 14, p. 7795, maio 2000.

SCHUMPETER, J.A. Teoria do desenvolvimento econômico. Tradução Maria Sílvia Possas. São Paulo: Nova Cultural, 1997.

SEBRAE. Fatores condicionantes e taxa de mortalidade de empresas no Brasil. S.L. 2005. Disponível em: <www.sebrae.com.br>. Acesso em: 08 nov. 2007. 
O super simples. 2008a. Disponível em: <www.sebrae.com.br>. Acesso em: 13 jan. 2009.

MPEs Brasil. 2006. Disponível em: <www.sebrae.com.br>. Acesso em: 20 jun. 2008.

Dez anos de monitoramento da sobrevivência e mortalidade de empresas. 2008b. Disponível em: <www.sebrae.com. br>. Acesso em: 03 nov. 2008.
SILVA, M. C. da. Micro e pequenas empresas na Bahia: uma análise da sobrevivência e geração de empregos. Conjuntura e Planejamento, Salvador: SEI, n.123, p.35-38, ago. 2004.

SOUZA, N. J. de. Desenvolvimento

econômico. 3. ed. São Paulo: Atlas, 1997.

. Desenvolvimento econômico. 4. ed. São Paulo: Atlas, 1999. 